of a star of a given sub-type is a function of its luminosity. Then since in any practical observational programme the range of apparent brightness in the stars observed is necessarily small, so that luminosity correlates partially with distance (see (1)), the colour will seem to be a function of distance. But this is just what would be expected if space absorption in the line of sight causes reddening. Is, then, some at least of the observed colour excess to be attributed to a luminosity effect ? Evidence on this point has hitherto been conflicting, but by investigation of the colours of stars in galactic clusters, where no question of differential space reddening arises, it has been established ${ }^{6}$ that for early-type stars the dependence of colour on luminosity is very small. Luckily these stars are just the ones which can be seen at great distances; they are therefore invaluable for investigating space absorption.

Advantage has been taken of this fact in two recent publications ${ }^{3,5}$ dealing with the colours of $B$-type stars. The main conclusions of both papers agree, though the treatment of the data differs somewhat. The distribution of the scattering particles is far from uniform ; for example, it does not resemble that of the interstellar calcium ions, which are so well scattered that the strength of the 'detached' lines they produce in the spectra of distant stars is perhaps the best available measure of large stellar distances. Most of the heavily reddened stars are in low galactic latitudes, so that the material must be confined fairly closely to the plane of the galaxy. The absorption in the plane itself varies considerably with galactic longitude, and even at one particular longitude seems to be only roughly proportional to distance. This large dispersion in the correlation between colour excess and distance for a given direction in space leads Stebbins and his collaborators? to suggest that a mean coefficient of selective absorption can have little significance-a conclusion which throws doubt on the validity of many recent investigations based on such a mean. Hunter and Martin ${ }^{5}$, however, trace much of the dispersion to uncertainty in the stellar distances. When this is allowed for, more than 90 per cent of their stars fit a linear correlation satisfactorily, and the abnormal colorations of many of the remainder can be accounted for by the presence of absorbing clouds for which independent evidence exists.

Whichever view is ultimately found to be correct, it is evident that the problem of space absorption is much more complicated than had been supposed even a decade ago. However, the main conclusions are now emerging : confined to within a few hundred parsecs of the plane of the galaxy, and extending in that plane to at least two or three thousand parsecs from the sun, there is an irregular stratum of dust particles which dims and reddens the light from stars. embedded in it. In addition to this stratum, there are the galactic nebulæ and dark obscuring clouds which outline the zone of avoidance of the extragalactic nebulæ. The effects of these two sources of absorption combine to reduce by a factor of two or more $^{2}$ the diameter previously assigned to our stellar system. The size of the dominant particle in the reddening stratum is about the wave-length of visible light ; in some at least of the dark nebulæ there are larger particles producing non-selective absorption. The distribution of the absorbing material is so irregular that many observational results are at present in apparent contradiction; and before the generalizations noted above can be added to with certainty, much more observational work must be carried out.

${ }^{1}$ Dunham, T., Proc. Amer. Phil. Soc., 81, 277 (1939).

¿Seares, F. H., Publ. Astr. Soc. Pacif., 52, 80 (1940).

${ }^{3}$ Stebbins, J., Huffer, C. M., and Whitford, A. E., Astrophys. J., 90, 209 (1939).

- Barbier, D., and Chalonge, D., C. R., 210, 166 (1940).

s Hunter, A., and Martin, E. G., Mon. Not. Roy. Astr. Soc., 100, 669 (1940).

- Hunter, A., and Martin, E. G., Mon. Not. Roy. Astr. Soc., 100, $656(1940)$

'Stebbins, J., Huffer, C. M., and Whitford, A. E., Astrophys. J., 92, 193 (1940)

\title{
DAM CONSTRUCTION IN THE TENNESSEE VALLEY
}

\begin{abstract}
$\mathrm{T}^{\mathrm{T}}$ RANSPORT, irrigation and electric power engineers all over the world are greatly interested in the Mississippi River system in the south-eastern part of the United States; and especially in the large-scale works which have been undertaken in the lower reaches with the view of alleviating the effects of the devastating floods which have frequently occurred. Mention has also been made of the controversy on the subject of the possible effects, on the lower river floods, of the construction of storage reservoirs in the upper reaches of important tributary streams.

In the issue of Engineering of January 3, there is published a map of the Tennessee Valley Authority's area showing the sites of the various dams which have been built, or are being built, on the river and its tributaries. In this connexion, it is of interest to note that, in House Document No. 1 of the 74th United States Congress, the president of the Mississippi River Commission is quoted as stating that "This Commission has recently submitted a separate report on a comprehensive system of tributary
\end{abstract}

reservoirs for control of floods in the lower Mississippi River. In this report it was shown that, in connexion with the existing levee system, substantially complete protection, except for backwater areas, might be obtained by such a tributary reservoir system."

Among the tributaries of the Mississippi the Tennessee River occupies an important place. Rising in the Clinch Mountains and flowing through Tennessee and Northern Alabama, it joins the Ohio River at Paducah, in Kentucky, some fifty miles above Cairo, where the Ohio flows into the Mississippi. The Tennessee Valley Authority controls the whole of the Tennessee River. Flood control was only one of the objectives of the Tennessee Valley Act of 1933, which created this Authority. It is also engaged, as is well known, in electric power production on a large scale and in the manufacture of nitrates at Muscle Shoals.

Potentially, the Tennessee River is an important waterway for navigation, and the control which is given by construction of dams is also of benefit in connexion with navigation of the Ohio and Mississippi 
Rivers. By the working out of what is considered to be the best economic compromise the works that are being carried out on the Tennessee River serve the three purposes of aiding navigation, flood control and the generation of electricity. An incidental result of the construction of large reservoirs has been the development of the Great Smoky Mountains National Park, one of the great recreational areas of the United States.

The construction of the Norris Dam was definitely authorized in the original legislation creating the Tennessee Valley Authority. It is situated on the Clinch River, about twenty miles north-west of Knoxville in Tennessee. The drainage area above the dam, which includes that of the Powell River, represents $7 \cdot 26$ per cent of the total area of 40,600 sq. miles of the Tennessee River basin. Work was begun on the dam in October 1933, and it was completed in June 1936.

The dam structure consists of a straight gravitytype mass-concrete section 1,560 ft. long, anchored to the solid rock on the west side of the gorge in which it is situated. At the east end it is connected to the hill-side by a $300 \mathrm{ft}$. length of rolled embankment with a concrete core wall, which is built into the concrete of the dam. A power house is situated at the base of the down-stream face of the dam. Alongside this is a spillway the section of which is $332 \mathrm{ft}$. wide. The thickness of the dam at its base is $204 \mathrm{ft}$. and its height, from the lowest point of the power house foundation to the level of the roadway along the top, is $265 \mathrm{ft}$. This roadway forms part of the highway system of the area. The spillway discharge is controlled by three hydraulically operated steel sector crest gates, each $100 \mathrm{ft}$. long by $14 \mathrm{ft}$. high. The gate openings are spanned by a concreteencased steel girder roadway bridge.

The normal impounded level of the reservoir above the dam is to elevation +1020, the crest of the spillway. This is also the level to which the water is allowed to rise for power storage, and gives a gross head of $194 \mathrm{ft}$. The volume of the reservoir above the dam between elevation +1020 and elevation $+962,58 \mathrm{ft}$. below, is $1,500,000$ acre-ft., this being the amount of water available for regulation of the power output and for navigation. This storage allows for an average contribution of 5,000 cusecs to the low-water flow of the Clinch and Tennessee Rivers, and an increase in the flow of the latter at Wilson Dam of 10,000-16,000 cusecs for 97 per cent of the year. With the regulation afforded by the Norris Dam, the extreme low-water flow at the Wilson Dam, below, is about 12,000 cusecs. By closing the spillway gates of the Norris Dam, water may be stored in the zone between elevation +962 and elevation +1047 . This gives a stored volume of $2,500,000$ acre-ft. When water is being impounded between these elevations, the outflow is maintained as nearly uniform as possible, and is not permitted to exceed 30,000 cusecs. This is equivalent to about bank-full conditions in the Clinch River.

The power house, which is approximately $70 \mathrm{ft}$. wide by $204 \mathrm{ft}$. long, contains two 56,000 kva. generating sets, supplied by the Westinghouse Electric and Manufacturing Company. They are rated at $50,000 \mathrm{kva}$. at 90 per cent power factor. By means of special electric relays, the exciter circuits can be opened and the generator brakes applied. The brakes can stop the machines in 15 minutes. The headings are practically air-tight, so that in emergency carbon dioxide fire-extinguishing equipment may be used.

\section{FORTHCOMING EVENTS}

[Meeting marked with an asterisk is open to the public.]

\section{Monday, February 3}

Royal Society of Arts (at John Adam Street, Adelphi, London, W.C.2), at 1.45 p.m.- Sir David Chadwick: "Some Problems of World Economic Development" (Cantor Lectures, 3).

Socrety of Chemicax Industry (at the Chemical Society's Rooms, Burlington House, Piccadilly, London, W.1), at 2 p.m.-Dr. E. F. Armstrong, F.R.S. : The first H. E. Armstrong Lecture.

Royal College of Surgeons of England (at the Royal Society of Medicine, 1 Wimpole Street, London, W.1), at 3 p.m.-Prof. F. Ronald Edwards: "Dried Plasma: its Preparation and Administration for the Syndrome of Shock".

Royal Geographical Society (at Kensington Gore, London, S.W.7), at 3 p.m.-Mr. Alan Browne: "Alpine New Zealand".

\section{Tuesday, February 4}

Chadwrck Trust (at the Royal Society of Tropical Medicine and Hygiene, 26 Portland Place, London, W.1), at 2.30 p.m.-Sir Walter Langdon-Brown: "Mental Health in War-Time".*

WARBURG Institute (at the Imperial Institute Buildings, South Kensington, London, S.W.7), at! 2.30 p.m.-Dr. F. Saxl : "Mithras-The History of an Indo-European Divinity".

\section{Thursday, February 6}

Royal Socrety (at Burlington House, Piccadilly, London, W.1), at 2.30 p.m.-Discussion on "Diffuse Reflections of X-rays by Crystals". To be opened by Sir William Bragg, O.M., F.R.S. Probable speakers : Prof. J. D. Bernal, F.R.S., Prof. Max Born, F.R.S., Sir Lawrence Bragg, F.R.S., Dr. C. G. Darwin, F.R.S., Dr. H. A. Jahn, Dr. K. Lonsdale, Dr. G. D. Preston.

\section{APPOINTMENTS VACANT}

APPLICATIONS are invited for the following appointments on or before the dates mentioned:

Assistant to the Adyisory OFFicer in ANimal HuSBandRY The Secretary, West of Scotland Agricultural College, 6 Blythswood Square, Glasgow (February 10).

Graduate assistant Teacher for Mechanical Enginegring SoBJEcts-The Principal, Acton Technical College, High Street, Acton, London, W.3 (February 10).

DEMONSTRATOR IN ANATOMY-The Registrar, University, Sheffield (March 1).

EXAMINER (Physicist) in the A.X.D. Test House, Harefield (nonmetallic Materials section)-The Secretary, Ministry of Aircraft Production, A.I.D.-I.C.S.I(T), Leatherhead, Surrey.

Technical Assistant (male) in the Department of EconomicsThe Secretary, South Eastern Agricultural College, Wye, Ashford Kent.

\section{REPORTS AND OTHER PUBLICATIONS}

(not included in the monthly Books Supplement)

Great Britain and Ireland

New Beginnings: a Scheme of Study for the Year 1941 for Adult Schools. Pp. viii +225 . (London: National Adult School Union.) 18. $6 d$. net.

A Study of the Diet and Social Conditions of the Working-class Families in Newcastle-upon-Tyne. By Najib U. Khan (Newcastle-upon-Tyne: The Dispensary.) 18. 1. Khan. Pp. 40.

\section{Other Countries}

Report of the King Institute of Preventive Medicine, Guindy, for the Year ending 30 th September 1939 , by Lt.-C'ol. H. E. Shortt; and Report of the Government Analyst, Madras, by Herbert Hawley. Pp.
$83+6$. (Madras: Government Press.) 8 annas.
[2412

Survey of India. Geodetic Report, 1939. Pp. v+66+13 plates. 3 rupees; $5 \delta$. Professional Paper No. 30: Gravity Anomalies and the Figure 5 . . Professional Paper No. 30 : Gravity Anomalies and 58. (Dehra Dun: Survey of India.) 